\title{
Mesoporous silica nanoparticles synthesized from liquid crystal display manufacturing extracts as a potential candidate for a drug delivery carrier: evaluation of their safety and biocompatibility
}

\author{
This article was published in the following Dove Press journal: \\ International Journal of Nanomedicine \\ 10 October 2013 \\ Number of times this article has been viewed
}

\author{
Yu-Chih Lin' \\ Liang-Yi Lin ${ }^{2}$ \\ Ming-Yi Gao ${ }^{3}$ \\ Yi-Ping Fang ${ }^{3}$ \\ 'Department of Environmental \\ Engineering and Health, Yuanpei \\ University, ${ }^{2}$ Institute of Environmental \\ Engineering, National Chiao \\ Tung University, ${ }^{3}$ Department of \\ Biotechnology, Yuanpei University, \\ Hsinchu, Taiwan
}

\begin{abstract}
Mesoporous silica nanoparticles (MSNs) were synthesized as a promising drug delivery carrier due to the large surface area and porous characteristics. Our previous study successfully recycled wastes from the liquid crystal display (LCD) industry as the silica precursor. In this study, we substantiated the possibility of applying this material as a drug carrier. MSNs synthesized from the extraction of wastes from the manufacture of LCD panels were characterized as having an average diameter of $100 \mathrm{~nm}$, a surface area of $788 \mathrm{~m}^{2} / \mathrm{g}$, a uniform pore size distribution of $3.8 \mathrm{~nm}$, and a pore volume of up to $1.04 \mathrm{~cm}^{3} / \mathrm{g}$. Methotrexate and camptothecin were entrapped in MSNs at about 33.88\% and 75.12\%, respectively. The cell viability assay demonstrated that MSNs at $1 \mu \mathrm{g} / \mathrm{mL}$ had no significant influence on human lung fibroblast (WI-38) cells or ovarian cancer (ES-2) cells. A lactate dehydrogenase assay also indicated no inflammation occurred. Moreover, a hemolytic erythrocyte test indicated that the dose range of $<100 \mu \mathrm{g} / \mathrm{mL}$ showed that $5 \%$ of erythrocytes were affected. After exposure to biofluids, the ordered structure was slightly degraded. The results revealed that MSNs synthesized from extraction of wastes from the manufacture of LCD panels had a good entrapment capacity for hydrophobic drugs and controllable safety conditions; they may be applied as a drug delivery carrier.
\end{abstract}

Keywords: mesoporous silica nanoparticles (MSNs), waste recycle, drug delivery carrier, safety, biocompatibility

\section{Introduction}

Because of their great surface area, large pore diameters, and uniform pore structures, mesoporous silica nanoparticles (MSNs) are utilized for adsorption, separation, catalysis, and sensors in various chemical reactions. ${ }^{1}$ The most common MSNs, such as Mobil Crystalline Material (MCM)-41, ${ }^{2}$ MCM-48, ${ }^{3}$ Santa Barbara amorphous silica (SBA)-15, ${ }^{4}$ Michigan State University silica (MSU)-n, ${ }^{5}$ and folded sheet-derived mesoporous silica (FSM)-16, ${ }^{6}$ were studied in the environmental protection field. Silicon alkoxides ${ }^{7}$ and sodium silicate ${ }^{8}$ are common silica sources; however, from the viewpoint of environmental resource protection, the current trend is towards recycling wastes containing silica or silicon as precursors for synthesizing mesoporous $\mathrm{SiO}_{2}$, instead of using commercial agents. For example, fly $\operatorname{ash}^{9-11}$ and rice husks ${ }^{12}$ can be utilized as precursors to synthesize mesoporous $\mathrm{SiO}_{2}$ characterized by a hexagonal pore arrangement with a high surface area. In addition, the semiconductor and photoelectric industries in Taiwan are world-famous industries; large amounts of waste are also produced with increasing yields. Recently, MSNs have attracted much attention in the
Correspondence: Yi-Ping Fang Department of Biotechnology, Yuanpei University, 306 Yuanpei St, Hsinchu, 300I5, Taiwan

$\mathrm{Tel}+8863538$ II 83 ext 8150 Fax +88636102312

Email ypfang@mail.ypu.edu.tw 
biomedical field due to their unique characteristics; ValletRegi et al applied MCM-41 as a carrier in a drug delivery system. ${ }^{2}$ Due to the versatile properties of MSNs, including a high Brunauer-Emmett-Teller (BET) surface area, a large pore volume, and uniform porosity, MSNs are excellent carrier candidates for encapsulation and release of a variety of active pharmaceutical ingredients (APIs). ${ }^{13,14}$

Nano-enabled drug delivery systems are being applied in the pharmaceutical industry since nanoparticle-based drugs may have improved solubility and altered pharmacokinetics and biodistributions compared to small-molecule drugs. ${ }^{15}$ The most interesting chemical properties of MSNs are the large specific surface area and large pore volume which have a high capacity for loading APIs in the inner pore system. MSN carriers used in drug delivery applications can provide several advantages including achievement of a sustained or controlled release, improved solubility of poorly soluble drugs, protection of the biological payload from physiological degradation, and a volumetric drug reservoir. ${ }^{16}$ With clinical chemotherapy, the main problem is the rapid therapeutic drug release or dumping from the vehicle or matrix before reaching the targeted site, which can cause systemic side effects. MSN surfaces suitably decorated with recognition moieties, such as antibodies, ${ }^{17}$ ligands, and polyethylene glycol (PEG), could achieve specific targeting. The functionalized process avoids nonspecific drug distribution throughout the body and minimizes side effects, while improving the therapeutic efficacy. ${ }^{18}$

Lin et al ${ }^{19,20}$ successfully recycled wastes from the liquid crystal display (LCD) industry as a silica precursor, and synthesized an efficient mesoporous adsorbent for $\mathrm{CO}_{2}$ capture. Moreover, the other elements also ensured that no significant residuals were present in the MSNs. Building on previous experience, the current study focused on safety and biocompatibility evaluations of MSNs synthesized from extraction of wastes from the manufacture of LCD panels to substantiate possible applications as drug carriers. Material characterizations of the pore structure, specific surface area, and pore volume were determined by the BET method using nitrogen adsorption-desorption isotherms. The safety assay utilized a cell viability test on a normal human lung fibroblast (WI-38) cell line and a human ovarian cancer (ES-2) cell line, and hemolysis of erythrocytes was also evaluated. The entrapment efficiencies $(\mathrm{EE} \%)$ of two hydrophobic drugs were measured by a centrifugation method. In order to understand changes in the pore structure of MSNs when administrated by oral or intravenous injection through gastric, intestinal, or plasma routes, the crystalline structure of MSNs was examined by powder X-ray diffraction and transmission electron microscopy (TEM).

\section{Experimental procedures Materials}

Waste powder from the manufacture of LCD panels was provided by a thin-film-transistor LCD manufacturer in the Hsinchu Science Industrial Park, Hsinchu, Taiwan. There was no decontaminated treatment of these powders in the factory. Methotrexate anhydrous basis (MTX), camptothecin (CPT), and hexadecyltrimethylammonium bromide (CTAB, $89 \%$ ) were purchased from Sigma-Aldrich (St Louis, MO, USA). Sulfuric acid (98\%, reagent of special grade) was from Shimakyu Co., (Osaka, Japan). Other chemicals used in the study were of reagent grade. Human lung fibroblast (WI-38) cells and human ovarian cancer (ES-2) cells were purchased from the Culture Collection and Research Center of the Food Industry Research and Development Institute (Hsinchu, Taiwan). Cell culture media and supplements were obtained from Life Technologies (Carlsbad, CA, USA).

\section{Preparation of MSNs}

Waste silica powder obtained from thin-film-transistor LCD was utilized to synthesize MSNs, and the template in the synthesis process of mesoporous structure was chosen as CTAB. Briefly, the synthesis procedure of MSNs was described as below; $9.35 \mathrm{~g}$ of waste silica powder was prepared, added, and stirred in $137 \mathrm{~mL}$ of deionized (DI) water. Subsequently, a given amount of hydrofluoric acid was added; in addition, $7.28 \mathrm{~g}$ of CTAB was prepared and dissolved in $25 \mathrm{~mL}$ of DI water, and then dropped into the solution. Then, $32.06 \mathrm{~g}$ of ammonium hydroxide solution was added to enhance the hydrolytic condensation of the silica-surfactant precursor. The molar ratio and the composition of the synthesis precursor were $1 \mathrm{SiO}_{2}: 0.2 \mathrm{CTAB}: 10 \mathrm{HF}: 12 \mathrm{NH}_{4} \mathrm{OH}: 120 \mathrm{H}_{2} \mathrm{O}$. All of the above procedures were performed under continuous stirring. The resulting precursor was aged at $25^{\circ} \mathrm{C}$ for 8 hours; the resultant solid was recovered by filtration, washed with DI water, and dried in an oven at $110^{\circ} \mathrm{C}$ for 6 hours. Finally, the resultant solid was put in the furnace at $550^{\circ} \mathrm{C}$ for 6 hours to remove the organic template, and the MSNs could be obtained after the temperature cooled down to $25^{\circ} \mathrm{C}$. The schematic illustration of MSNs produced is shown in Figure 1.

\section{Material characterization of MSNs}

The pore size distribution was calculated from the adsorption branch of the $\mathrm{N}_{2}$ adsorption-desorption isotherm and the 




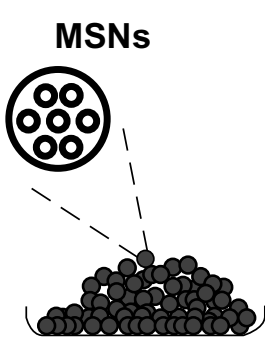

Figure I The schematic illustration of mesoporous silica nanoparticles formation. Abbreviation: MSNs, mesoporous silica nanoparticles.

Barrett-Joyner-Halenda (BJH) method. The specific surface area of the MSNs was determined by the BET method using nitrogen adsorption-desorption isotherms (ASAP 2020; Micromeritics Instrument Corporation, Norcross, GA, USA), and the pore volume was obtained by the t-plot method. The crystalline structure of the MSNs was observed by low-angle X-ray diffraction (LAXRD; D8 Discover; Bruker Corporation, Billerica, MA, USA), and surface observations were obtained by TEM (JEM-2000EX; JEOL, Tokyo, Japan).

\section{Cell viability assay}

The percent cell survival was determined with a 3,(4,5-dimethylthiazol-2-yl)2,5-diphenyltetrazolium bromide (MTT) assay, which produces formazan crystals in mitochondria within cells. Human lung fibroblast (WI-38) and human ovarian cancer (ES-2) cells were respectively seeded in minimum essential medium $\alpha$ and Roswell Park Memorial Institute 1640 medium on 24-well plates at a cell density of $2 \times 10^{4}$ cells/well until cells were confluent. Medium was replaced by MSN suspensions at different concentrations for 24 hours at $37^{\circ} \mathrm{C}$ in air containing $5 \% \mathrm{CO}_{2}$. Then we added $200 \mu \mathrm{L}$ of the MTT solution $(0.5 \mathrm{mg} / \mathrm{mL})$ to each well and incubated the wells for 2 hours. In order to dissolve the water-insoluble formazan, MTT/medium was removed from each well, and $500 \mu \mathrm{L}$ of dimethyl sulfoxide was added to each well. The extent of cell survival was determined by an enzyme-linked immunosorbent assay reader at $595 \mathrm{~nm}$.

\section{Drying process}

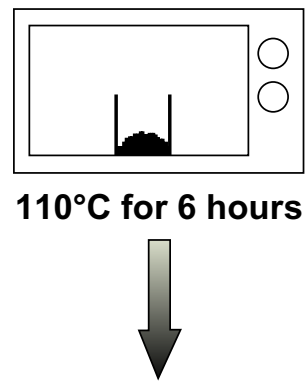

Furnace

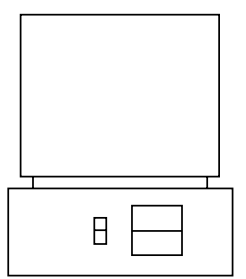

$550^{\circ} \mathrm{C}$ for 6 hours

\section{Lactate dehydrogenase assay}

Lactate dehydrogenase (LDH) release was determined by a commercially available method (Promega Corporation, Fitchburg, WI, USA). A cell density of $2 \times 10^{4}$ cells/well was exposed to various concentrations of MSNs for 24 hours. The total LDH released was determined by lysing cells with $0.1 \%$ Triton $\mathrm{X}-100$ for 30 minutes at $37^{\circ} \mathrm{C}$. Inflammation was represented by $\mathrm{LDH}$ release in a cell-free medium as a percentage of the total LDH release. The activity of extracellular LDH was measured at $490 \mathrm{~nm}$.

\section{Erythrocyte hemolysis}

Blood samples, obtained from healthy human volunteers, were collected into VACUTAINER ${ }^{\mathrm{TM}}$ tubes (BD Co., Ltd, Franklin Lakes, NJ, USA). Erythrocytes were separated from blood samples by centrifugation at 2,000 rpm for 5 minutes and washed four times with phosphate-buffered saline (PBS). Following the last wash, red blood cells (RBCs) were dispersed in PBS (v/v, 1/9) as the erythrocyte stock. The RBC stock $(100 \mu \mathrm{L})$ was mixed with $50 \mu \mathrm{L}$ of sample and $2.45 \mathrm{~mL}$ of PBS, and the mixture was incubated at $37^{\circ} \mathrm{C}$ for 1 hour, and then centrifuged at 2,000 rpm for 5 minutes to separate hemoglobin from complete and incomplete erythrocytes. The absorbance of the supernatant (hemoglobin) was measured with a spectrophotometer at $415 \mathrm{~nm}$. Erythrocytes were dissolved in double-distilled water as a positive control (100\% hemolysis) and in PBS as a negative 
control ( $0 \%$ hemolysis). The percentage of hemolysis was calculated as follows:

$$
\left(\frac{\mathrm{X}-\text { control PBS }}{\text { control } \mathrm{H}_{2} \mathrm{O}}\right) \times 100 \% \text {, }
$$

where $\mathrm{X}$ is the value of hemoglobin.

\section{TEM}

The morphology of original MSNs was examined by TEM to characterize the microstructure. MSNs were incubated at $37^{\circ} \mathrm{C}$ and shaken at $50 \mathrm{rpm}$ in an incubator in various fluids, including $0.1 \mathrm{~N} \mathrm{HCl}$ for 1 hour to simulate gastric fluid and at $\mathrm{pH} 6.8$ for 4 hours to simulate intestinal fluid. Original MSNs were suspended in double-distilled water, and those cells were applied to a carbon film-covered copper grid. After drying, the sample was examined by TEM (JEM-2000EX; JEOL).

\section{LAXRD}

In order to measure the crystal structure of MSNs, LAXRD was performed. After the same pretreatment process as for TEM, the sample was washed with double-distilled water in a centrifuge at 5,000 rpm for 10 minutes, and then the supernatant was removed. The centrifugation process was repeated three or four times. MSN pellets were dried at $50^{\circ} \mathrm{C}$ for 8 hours. The sample was examined by LAXRD (D8 Discover; Bruker) with $\mathrm{CuK} \alpha$ radiation $(\lambda=0.154 \mathrm{~nm})$ at a $2 \theta$ angle range of $0^{\circ}-10^{\circ}$ to measure the crystal structure.

\section{Loading drugs into MSNs and determining the $\mathrm{EE} \%$}

MTX and CPT were separately used as model drugs, and effects of different concentrations of drugs of $0.01,0.05$, and $0.1 \mathrm{mg} / \mathrm{mL}$ loaded into MSNs were examined. The model drug molecules were loaded into pores of MSNs by soaking in a solution containing MTX or CPT for 12 hours. MTX or CPT was pre-dissolved in absolute ethanol or 30\% ethanol, respectively. The EE\% utilized a centrifugation method to separate the incorporated drug from the free form. Vesicle suspensions were centrifuged at 15,000 rpm for 30 minutes. Following centrifugation, non-incorporated free drug was in the supernatant, and the pellet was washed three or four more times. Amounts of free drug and entrapped drug were analyzed by high-performance liquid chromatography (HPLC) to determine the EE\%, which was calculated by the following equation:

$$
\begin{aligned}
& \text { EE } \% \\
& =\left(\frac{\text { Total amount of drug }- \text { Free amount of drug }}{\text { Total amount of drug }}\right) \times 100 \%
\end{aligned}
$$

\section{Quantification of drugs by HPLC}

Model drug contents of the various samples were analyzed with an HPLC system consisting of an L-7110 pump, an L-7200 sample processor, an L-7485 ultraviolet detector, and an L-7485 fluorescence detector (all from Hitachi Ltd, Tokyo, Japan). For MTX determination, a $25 \mathrm{~cm}$ long, $4 \mathrm{~mm}$ inner diameter stainless steel RP-18 column (Merck KGaA, Darmstadt, Germany) was used. The mobile phase consisted of acetonitrile-water-tetrahydrofuran (65: $30: 5 \mathrm{v} / \mathrm{v} / \mathrm{v})$ at $\mathrm{pH} 3.0$ adjusted with phosphoric acid at a flow rate of $0.8 \mathrm{~mL} / \mathrm{minute}$. The ultraviolet detector was set to a wavelength of $313 \mathrm{~nm}$. For CPT determination, a $25 \mathrm{~cm}$ long, $4 \mathrm{~mm}$ inner diameter stainless steel RP-18 column (Merck) was used. The mobile phase was an acetonitrile: $\mathrm{pH} 4$ aqueous solution adjusted with acetic acid (35:65) at a flow rate of $1.0 \mathrm{~mL} /$ minute. Wavelengths of excitation and emission were set to 360 and $440 \mathrm{~nm}$.

\section{Statistical analysis}

All data are expressed as the mean \pm standard derivation. Statistical analyses were performed using an unpaired Student's $t$-test with WINKS SDA 6.0 software (TexaSoft, Duncanville, TX, USA). A 0.05 level of probability was used as the level of significance. An analysis of variance test was also used.

\section{Results and discussion}

MSNs are well-known inorganic materials, which provide large spaces as drug delivery carriers. Our past research explored MSNs synthesized from the extraction of waste from the manufacture of LCD panels as an excellent $\mathrm{CO}_{2}$ adsorbent. ${ }^{19,20}$ Synthesized MSNs possessed mesoporous properties of about $100 \mathrm{~nm}$ in average diameter, a surface area of $788 \mathrm{~m}^{2} / \mathrm{g}$, a uniform pore size distribution of $3.8 \mathrm{~nm}$, and a pore volume of up to $1.04 \mathrm{~cm}^{3} / \mathrm{g}$. MSNs were capable of encapsulating hydrophobic chemotherapeutic drugs including MTX and CPT, and after exposure to simulated biofluids, the ordered structure was degradable. These results demonstrate that MSNs synthesized by extraction from LCD panel manufacture wastes are biocompatible for application as drug carrier candidates.

\section{Physicochemical characterization of MSNs}

An illustration of the $\mathrm{N}_{2}$ adsorption-desorption isotherms of MSNs is shown in Figure 2. It is clear that MSNs exhibited 
type IV isotherms which was characteristic of mesoporous materials, featuring a narrow step due to capillary condensation of $\mathrm{N}_{2}$ within the primary mesopores. ${ }^{21,22}$ The isotherms of the MSNs also indicated the type H1 hysteresis loop associated with well-arranged cylindrical channels with uniform shape and pore size. ${ }^{23}$ Figure 2 also showed the BJH pore size distributions of MSNs. It is clear that the MSNs also showed a narrow pore size distribution with the peak size at around $3.5 \mathrm{~nm}$, and the mesostructure of MSNs was very uniform. The physicochemical properties of BET specific surface area, specific pore volume, and average pore diameter derived from the $\mathrm{N}_{2}$ adsorption-desorption measurements are summarized in Table 1. Table 1 lists an average particle diameter of MSNs of $100 \mathrm{~nm}$, a specific surface area of $788 \mathrm{~m}^{2} / \mathrm{g}$, an average pore diameter of $3.8 \mathrm{~nm}$ by the $\mathrm{BJH}$ analysis, and a pore volume of $1.04 \mathrm{~cm}^{3} / \mathrm{g}$. To observe the microstructure, a TEM analysis was also performed. Figure $3 \mathrm{~A}$ shows the original silica source of MSNs which have a nanometersized spherical outline and uniform shapes. The images also revealed that MSNs possess a worm-like structural order with a mean diameter of $100 \mathrm{~nm}$ at magnifications of $40,000 \times$ and $80,000 \times$.

\section{Cell viability and $\mathrm{LDH}$ release}

We screened both the WI-38 and ES-2 cell lines to understand the cytotoxicity of MSNs, as shown in Figure $4 \mathrm{~A}$ and $\mathrm{B}$. When $1 \mu \mathrm{g} / \mathrm{mL}$ of MSNs was added to WI-38 cells, there was no significant change compared to the control group $(P>0.05)$. The addition of $5 \mu \mathrm{g} / \mathrm{mL}$ and $10 \mu \mathrm{g} / \mathrm{mL}$ of MSNs reduced the viability of the WI-38 cells to $82 \%$ and $84 \%$, respectively, whereas at $50 \mu \mathrm{g} / \mathrm{mL}$, the viability of the WI-38 cells significantly decreased to $34 \%$ $(P<0.001)$. On the other hand, $1 \mu \mathrm{g} / \mathrm{mL}$ and $5 \mu \mathrm{g} / \mathrm{mL}$ of MSNs did not produce significant changes in ES-2 cells. When concentrations were increased to $10 \mu \mathrm{g} / \mathrm{mL}$ and $50 \mu \mathrm{g} / \mathrm{mL}$, cell viabilities were respectively reduced to $84 \%$ and $46 \%$.

Since inflammation may elevate LDH release, we studied the influence of the MSNs concentration in both normal WI-38 cells and ES-2 cancer cells. The percentage of LDH was measured after exposure of WI-38 cells to various concentrations of MSNs for 24 hours. The LDH results also presented the same trend as the MTT assays, as shown in Figure 5A and B. After exposure to MSNs at $1 \mu \mathrm{g} / \mathrm{mL}$ to $10 \mu \mathrm{g} / \mathrm{mL}$, there were no significant differences compared to the blank $(P>0.05)$;

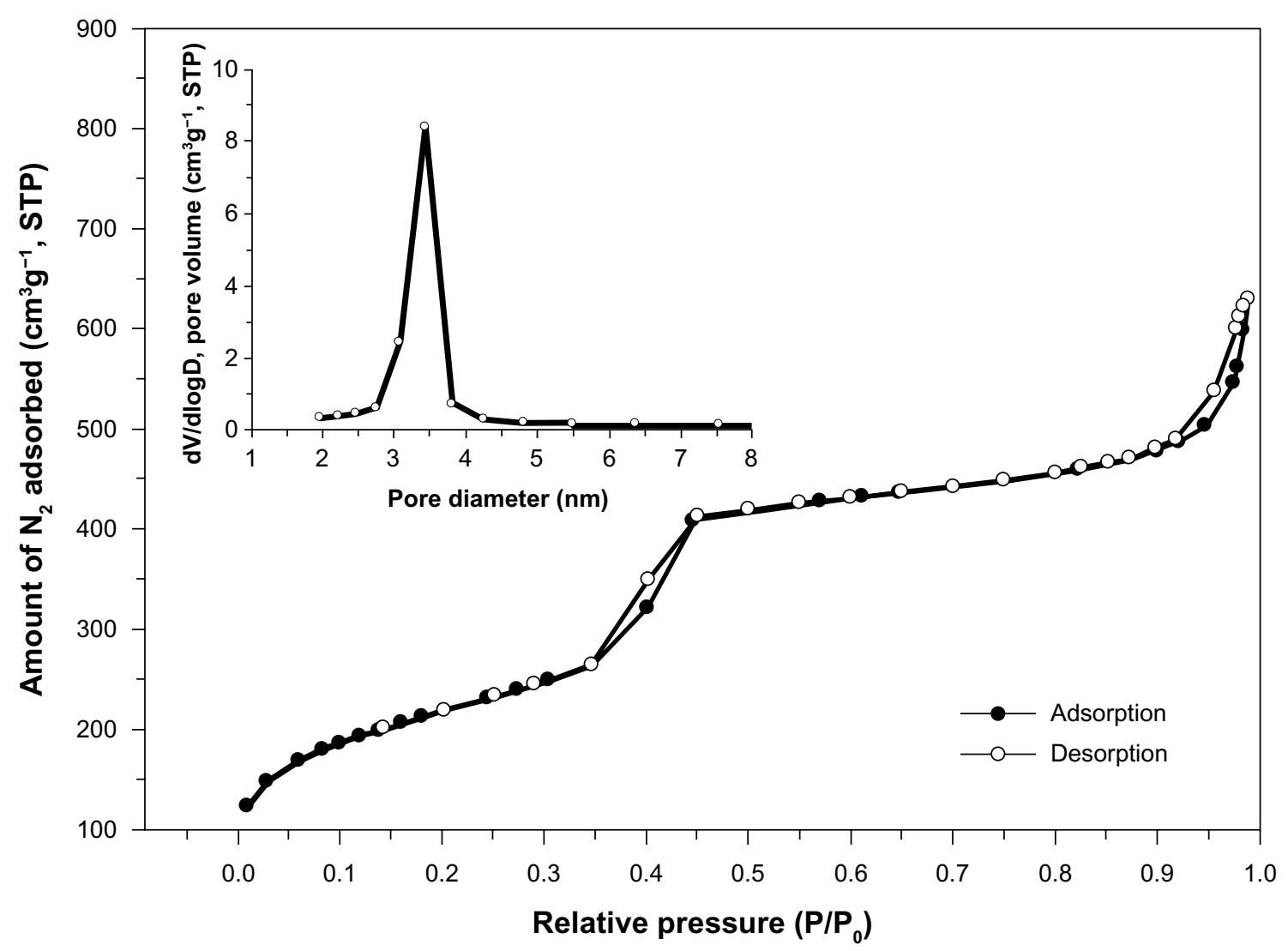

Figure 2 The $\mathrm{N}_{2}$ adsorption-desorption isotherm and $\mathrm{BJH}$ pore diameter distribution of the MSNs. Abbreviations: $\mathrm{BJH}$, Barrett-Joyner-Halenda; MSNs, mesoporous silica nanoparticles. 
Table I Structural parameters of mesoporous silica nanoparticles

\begin{tabular}{lll}
\hline $\mathbf{S}_{\text {BET }}$ & $\mathbf{d}_{\mathbf{B J H}}$ & $\mathbf{V p}$ \\
\hline $788 \mathrm{~m}^{2} / \mathrm{g}$ & $3.8 \mathrm{~nm}$ & $1.04 \mathrm{~cm}^{3} / \mathrm{g}$ \\
\hline
\end{tabular}

Abbreviations: $d_{B \mid H}$, mean pore diameter measure via Barret-Joyner-Halenda method; $S_{B E T}$, specific surface area measured via the Brunauer-Emmett-Teller method; $V_{p}$, pore volume.

however, with $50 \mu \mathrm{g} / \mathrm{mL}$ of MSNs, LDH release significantly increased to $62.59 \% \pm 5.98 \%$ of the total value $(P<0.001)$. In ES-2 cells, LDH release had the same tendency. There were no significant differences when incubated with MSNs at $1-10 \mu \mathrm{g} / \mathrm{mL}$; however, when the MSNs concentration was increased to $50 \mu \mathrm{g} / \mathrm{mL}$, LDH significantly increased to $54.83 \% \pm 1.62 \%$ of the total value $(P<0.001)$.

Cell viability and LDH assays were designed to understand the cytotoxicity and inflammation, and exposure of WI-38 and ES-2 cells to $\mathrm{SiO}_{2} \mathrm{MSNs}$. At $1 \mu \mathrm{g} / \mathrm{mL}$ of $\mathrm{SiO}_{2} \mathrm{MSNs}$, there was no cytotoxicity after 24 hours of exposure. In contrast, exposure to $5-50 \mu \mathrm{g} / \mathrm{mL}$ significantly increased cell death, causing the viability of WI-38 and ES- 2 cells to remain at about $30 \%-50 \%$. LDH results were consistent for both WI-38 and ES-2 cells, which indicated that $\mathrm{SiO}_{2} \mathrm{MSNs}$ induced inflammation at the $50 \mu \mathrm{g} / \mathrm{mL}$ dose. On the other hand, exposure to $1-10 \mu \mathrm{g} / \mathrm{mL}$ showed no inflammatory phenomena.
Silica MSN materials are extensively used in a wide variety of applications including catalytic support, photonic crystals, gene delivery, photodynamic therapy, and the biomedical field, being particularly attractive as a drug delivery carrier. ${ }^{24}$ If employing $\mathrm{SiO}_{2}$ MSNs as an injectable drug delivery carrier, these nanoparticles must be $<100 \mathrm{~nm}$ in diameter to avoid immediate uptake by the reticuloendothelial system. ${ }^{25}$ However, much research indicated that amorphous mesoporous/nanoporous silica nanoparticles of $<50 \mathrm{~nm}$ in diameter reduced cell viability in an in vitro model. In addition, a previous study pointed out that ultrafine particles $(<15 \mathrm{~nm})$ had a greater ability to enhance pulmonary injury than fine particles $(>200 \mathrm{~nm})$ at the same chemical composition in an in vivo model. ${ }^{26}$ Past research proved that exposure to silica is associated with progressive pulmonary inflammation and fibrosis. We need to confirm a limiting dose for usage.

\section{Hemolysis}

The hemolysis assay was used to evaluate a safe dose when human erythrocytes are exposed to MSNs via intravenous administration. As shown in Figure 6, MSNs at $5 \mu \mathrm{g} / \mathrm{mL}$ produced $3 \%$ hemolytic activity, at $1,000 \mu \mathrm{g} / \mathrm{mL}$ produced $30 \%$ activity, and at $5,000 \mu \mathrm{g} / \mathrm{mL}$ produced $86 \%$ activity. The hemolysis percentage of erythrocytes increased in a dose-dependent
A

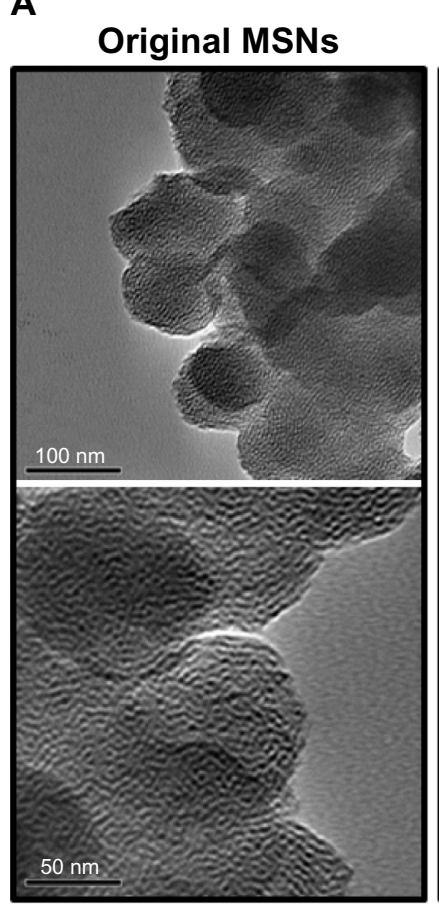

B
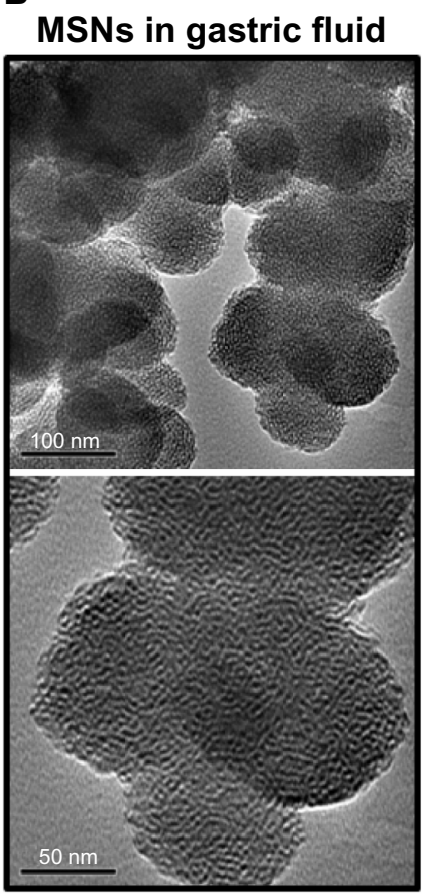

C
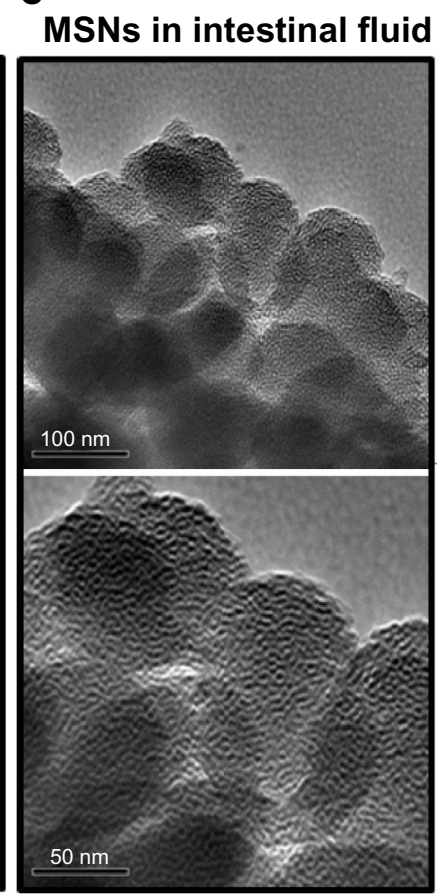

Figure 3 TEM images.

Notes: TEM images of (A) original MSNs, (B) MSNs incubated in simulated gastric fluid for I hour, and (C) MSNs incubated in simulated intestinal fluid for 4 hours. All of the upper panels were magnified 40,000x; lower panels were magnified 80,000x.

Abbreviations: MSNs, mesoporous silica nanoparticles; TEM, transmission electron microscopy. 

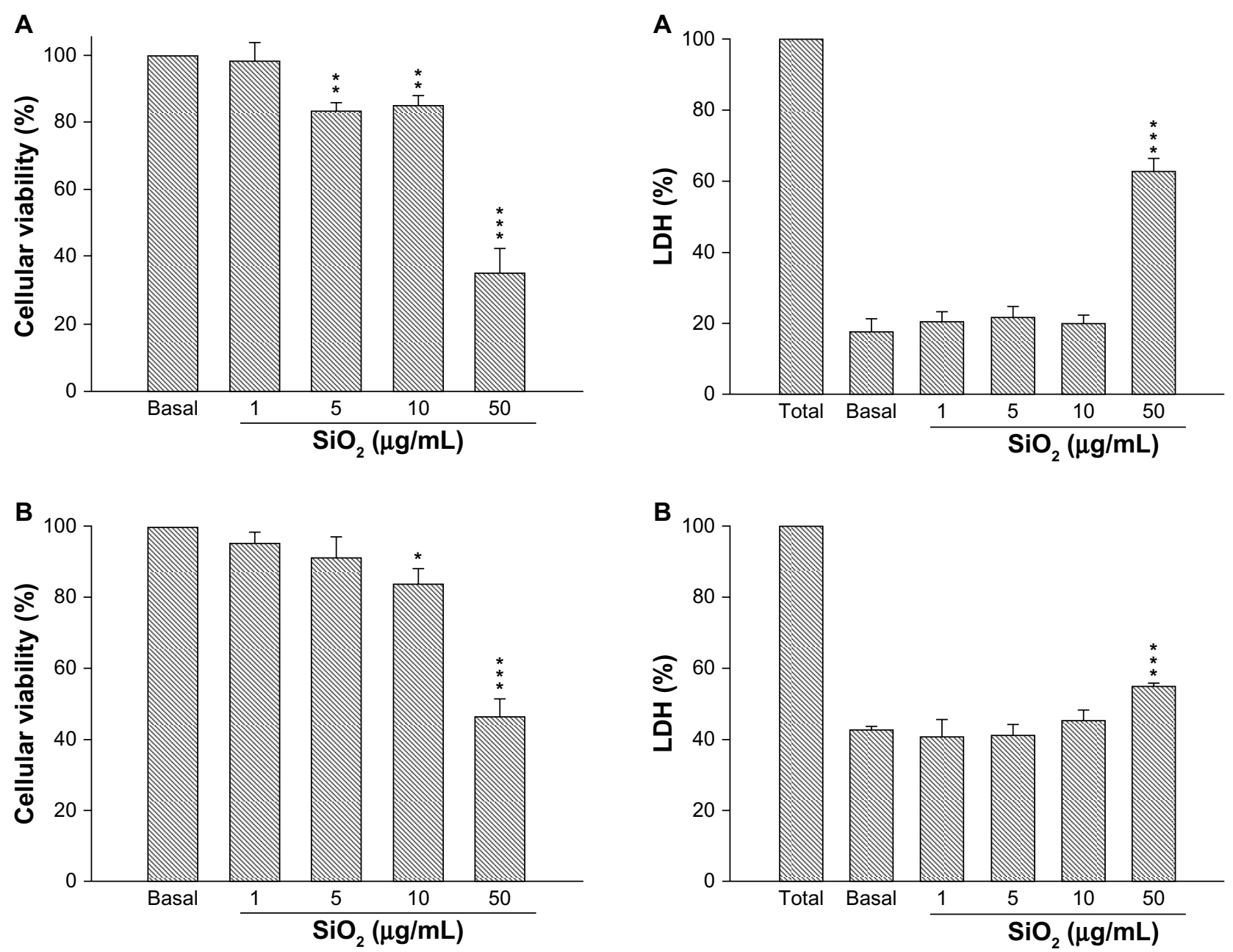

Figure 4 Cellular viability of mesoporous silica nanoparticles suspended in cell media at concentrations of $\mathrm{I}, 5,10$, and $50 \mu \mathrm{g} / \mathrm{mL}$ in (A) a human lung fibroblast (WI-38) cell line and (B) a human ovarian cancer (ES-2) cell line.

Notes: Cell viability was normalized by setting the viability of untreated cell to 100\%. Data are presented as the mean \pm standard deviation $(n=3)$. $* P<0.05$, $* * P<0.01, * * * P<0.001$.

manner. These data revealed a good linear correlation $(r=0.954)$ in the range of $5-5,000 \mu \mathrm{g} / \mathrm{mL}$ of MSNs.

Generally, a drug delivery carrier is administrated by an intravenous route, and the hemolysis of erythrocyte is a serious biosafety concern. ${ }^{27}$ To determine the concentration leading to lysis of erythrocytes by MSNs, human erythrocytes were incubated at a range of concentrations of $50-5,000 \mu \mathrm{g} / \mathrm{mL}$ for 1 hour. The in vitro results showed that the highest dose of $5,000 \mu \mathrm{g} / \mathrm{mL}$ of MSNs used in this study produced an $86 \%$ hemolytic effect. In contrast, at the lower doses of $5 \mu \mathrm{g} / \mathrm{mL}$ and $10 \mu \mathrm{g} / \mathrm{mL}$ of MSNs, hemolysis of RBCs was detected at about $3 \%-4 \%$. We discuss the relationship between hemolysis and MSNs from three aspects. (1) In terms of the amorphous structure, silica materials with amorphous particle morphology will cause hemolysis of mammalian RBCs. ${ }^{28}$ This kind of hemolytic behavior raises serious biosafety concerns

Figure $\mathbf{5}$ Inflammation assay by measuring LDH release from (A) human lung fibroblast (WI-38) cells and (B) human ovarian cancer (ES-2) cells treated with different concentrations of mesoporous $\mathrm{SiO}_{2}$ nanoparticles.

Note: $* * * p<0.001$.

Abbreviation: LDH, lactate dehydrogenase.

regarding the application of amorphous silica for drug delivery involving intravenous administration and transport. (2) In terms of functional groups on MSNs surfaces, most researchers agree that the hemolytic activity of silica is related to surface silanol groups. ${ }^{29}$ In the present study, our MSNs were pure silica, and no hydroxyl groups were connected to the Si. (3) In terms of particle size, previous studies indicated that larger particle sizes of about $250 \mathrm{~nm}$ may be preferable for MSNs hemocompatibility, ${ }^{24}$ and at about $600 \mathrm{~nm}$, strong local membrane deformation occurs leading to spiculation of the RBCs. ${ }^{30}$ According to the above points, $\mathrm{SiO}_{2}$ MSNs in the present work did not have an amorphous structure, there were no surface modifications on $\mathrm{SiO}_{2}$ MSNs with hydroxyl groups, and particle sizes were smaller than $100 \mathrm{~nm}$. Hence, $\mathrm{SiO}_{2}$ MSNs should not cause serious hemolytic effects when within controlled ranges. 
A
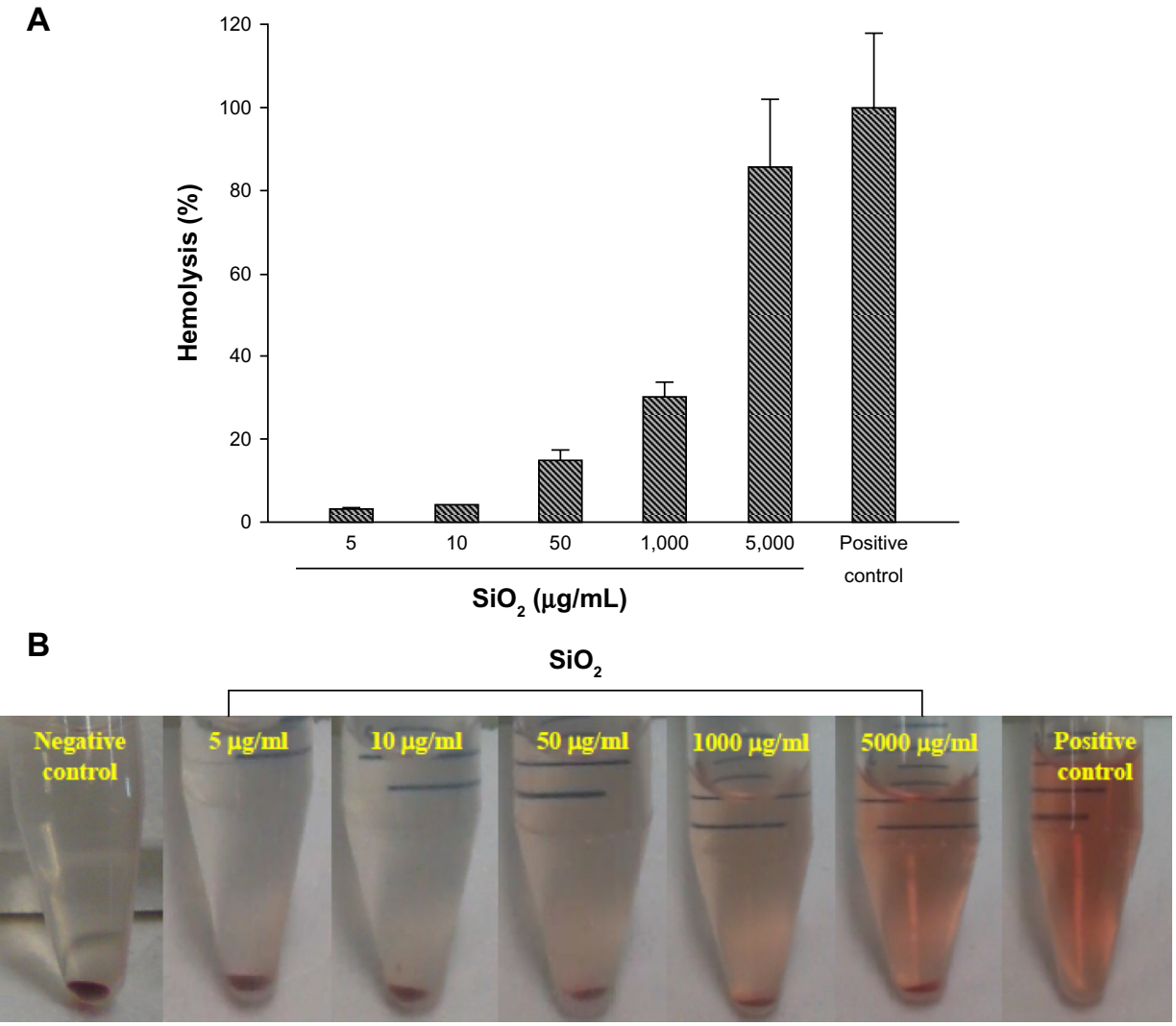

Figure 6 (A) Percentage of hemolytic human erythrocytes induced by different concentrations of MSNs at 5-5,000 $\mu g / \mathrm{mL}$. (B) Images of erythrocyte samples which had been centrifuged to detect free hemoglobin in the supernatants.

Note: Data are presented as the mean \pm SD $(n=3)$.

Abbreviations: MSNs, mesoporous silica nanoparticles; SD, standard deviation.

\section{EE\% of anticancer drugs}

MTX and CPT are used as potent chemotherapeutic agents in the clinic. However, because of the poor water solubility of these drugs, they do not dissolve in most biocompatible media, which obstructs delivery into tumor cells. Although synthesizing analogs by modifying the chemical structure is an alternative strategy, the irinotecan analog presented lower cytotoxicity toward cancer cells. ${ }^{31}$ In addition, an alternative strategy is to make hydrophobic drugs in a lyophilized powder form, a well-known method to resolve delivery problems. Unfortunately, a narrow therapeutic index and toxicity cause serve adverse reactions. For example, CPT needs to be resuspended in an alkaline solution before being intravenously injected, which significantly alters the toxicological profile of the drug. ${ }^{32}$ A clinical study clearly demonstrated that criteria of therapeutic drug monitoring need to be selected for MTX and CPT to optimize cancer chemotherapy. ${ }^{33}$ Hence, changes in the physicochemical properties of hydrophobic drugs are necessarily required.

In this work, we employed a novel calcination method to extract a silica precursor as MSNs, and investigated the
EE\% of the hydrophobic drugs, as shown in Table 2. The results showed that the respective EE\% values of MTX and CPT adsorbed in the MSNs were about $34 \%$ and $75 \%$, respectively. Some physicochemical-dependent manners exist between hydrophobic drugs and MSNs, such as the molecular weight, $\log$ P, polar surface area, and pKa. Basically, MSNs in this study presented a wormhole-like porous structure which produced a large specific surface area measured via BET method of $788 \mathrm{~m}^{2} / \mathrm{g}$. However, MTX presented a low entrapment efficiency compared to CPT. That may be attributed to MTX's structure with amino and carboxylic groups which interact with $\mathrm{SiO}_{2}$ through weak ionic interactions. On the other hand, CPT was highly entrapped in the MSNs, and the possibility of interactions between $\mathrm{CPT}$ and $\mathrm{SiO}_{2}$ molecules was considerable. The hydrocarbon moiety of the CPT structure may interact with $\mathrm{SiO}_{2}$ by hydrogen bonding forces. Typically, electronegative oxygen exists in $\mathrm{SiO}_{2}$, and oxygen has a partial negative charge, which may exhibit an affinity to interact with hydrogen atoms of CPT. Many hydrocarbon moieties exist in the CPT structure which can provide protons to interact with oxygens of $\mathrm{SiO}_{2}$. 
Table $2 \mathrm{EE} \%$ of the anticancer drugs, MTX, and CPT

\begin{tabular}{lll}
\hline $\begin{array}{l}\text { Concentration } \\
(\mathrm{mg} / \mathrm{mL})\end{array}$ & EE\% & \\
\cline { 2 - 3 } & MTX & CPT \\
\hline 0.1 & 33.88 & 75.12 \\
\hline
\end{tabular}

Abbreviations: CPT, camptothecin; EE\%, entrapment efficiency, MTX, methotrexate.

\section{Biocompatibility}

In order to understand the effects of MSNs after oral administration or intravenous injection into the circulation, the structural order of MSNs will be changed by various biofluids. Original MSNs synthesized from wastes from LCD panel manufacture are shown in Figure 7A, which present an ordered worm-like structure with a mean diameter of $100 \mathrm{~nm}$. On the other hand, the mean diameter and pore order of MSNs did not significantly change in simulated gastric or intestinal fluid on the microscopic scale.

Moreover, LAXRD was performed to confirm changes in the pore order in microscopic observations, since impurities exist in the plasma medium which can be observed by TEM. Although Figure 7B and C shows that MSNs incubated in gastric and intestinal fluids exhibited negligible changes, under LAXRD determination as shown in Figure 7, MSNs incubated in gastric fluid for 1 hour and intestinal fluids for 4 hours showed a slight decrease, particularly at the $1.9^{\circ}$ peak. LAXRD patterns of MSNs exposed to plasma for 24 hours were particularly distinctive at the $1.9^{\circ}$ peak and in the range

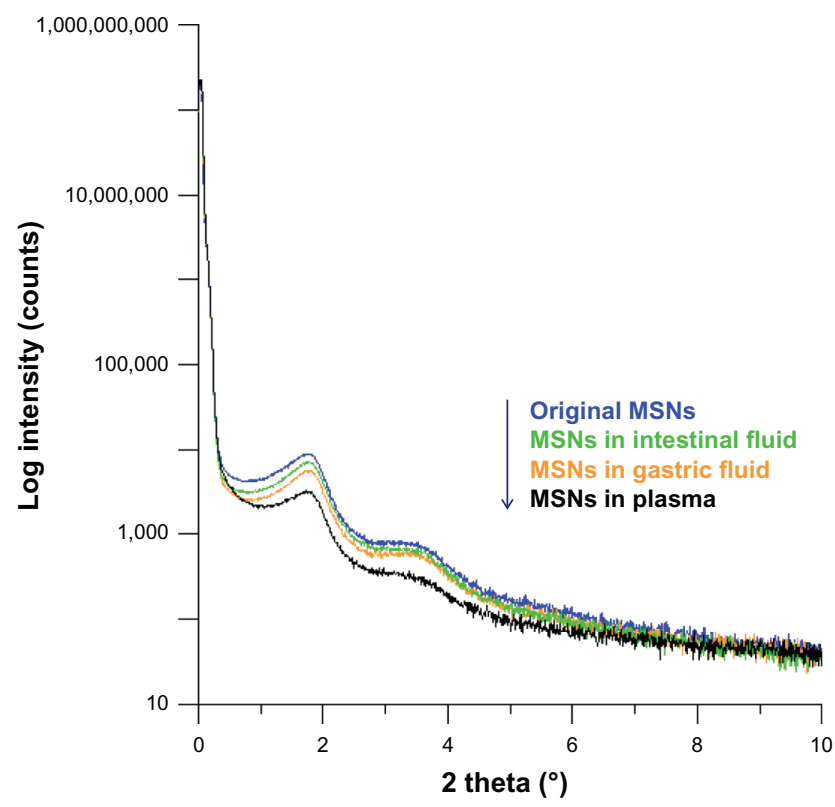

Figure 7 Low-angle X-ray diffraction patterns of original mesoporous silica nanoparticles which had been incubated in simulated gastric fluid for I hour, in intestinal fluids for 4 hours, and in plasma-like conditions for 24 hours.

Abbreviation: MSNs, mesoporous silica nanoparticles. of $2.5^{\circ}-4^{\circ}$. The results suggest that MSNs present slight biodegradable properties, particularly in gastric conditions and plasma circulation. This property is more important in relation to the design concept as to what kind of drug is suitable to be carried.

\section{Conclusion}

In summary, we utilized MSNs synthesized from extraction of wastes from the manufacture of LCD panels as a silica source for drug delivery carriers. This is pioneering work which successfully entrapped hydrophobic dugs in MSNs to overcome their water-insoluble properties. Moreover, exposure of MSNs to bio-conditions caused the ordered structure to become more degradable, especially in plasma conditions. This indicates that MSNs have good biodegradable properties. We also established dose limitations when applied as delivery carriers. The present study revealed that MSNs synthesized from extraction of wastes from the manufacture of LCD panels had good entrapment capacity for hydrophobic drugs and controlled safety conditions; they can be applied as a silica source for drug delivery carriers. There is a need for more in vivo assessments in a rat model with administration of MSNs orally or by injection to understand the changes in biochemical indicators and to investigate the pharmacokinetics. Also, the release behavior needs to be clarified.

\section{Acknowledgment}

We are grateful to Professor Tsong-Long Hwang, Laboratory of Cellular Pharmacology, Graduate Institute of Natural Products, College of Medicine, Chang Gung University, Taiwan, for assistance with the cellular cytotoxicity and inflammation assays.

\section{Disclosure}

The authors report no conflicts of interest in this work.

\section{References}

1. Tang F, Li L, Chen D. Mesoporous silica nanoparticles: synthesis, biocompatibility and drug delivery. Adv Mater. 2012;24(12): 1504-1534.

2. Vallet-Regi M, Rámila A, del Real RP, Pérez-Pariente J. A new property of MCM-41: drug delivery system. Chem Mater. 2001;13(2):308-311.

3. Huo Q, Leon R, Petroff PM, Stucky GD. Mesostructure design with gemini surfactants: supercage formation in a three-dimensional hexagonal array. Science. 1995;268(5215):1324-1327.

4. Zhao D, Feng J, Huo Q, et al. Triblock copolymer syntheses of mesoporous silica with periodic 50 to 300 angstrom pores. Science. 1998;279(5350):548-552.

5. Bagshaw SA, Prouzet E, Pinnavaia TJ. Templating of mesoporous molecular sieves by nonionic polyethylene oxide surfactants. Science. 1995;269(5228):1242-1244. 
6. Inagaki S, Fukushima Y, Kuroda K. Synthesis of highly ordered mesoporous materials from a layered polysilicate. J Chem Soc Chem Commun. 1993;8:680-682.

7. Beck JS, Vartuli JC, Roth WJ, et al. A new family of mesoporous molecular sieves prepared with liquid crystal templates. J Am Chem Soc. 1992;114(27):10834-10843.

8. Lin HP, Cheng S, Mou CY. Mesoporous molecular sieves MCM-41 with a hollow tubular morphology. Chem Mater. 1998;10(2):581-589.

9. Choi CL, Park M, Lee DH, Kim IE, Park BY, Choi J. Salt-thermal zeolitization of fly ash. Environ Sci Technol. 2001;35(13):2812-2816.

10. Chang HL, Chun CM, Aksay IA, Shih WH. Conversion of fly ash into mesoporous aluminosilicate. Ind Eng Chem Res. 1999;38(3): 973-977.

11. Hui KS, Chao CY. Synthesis of MCM-41 from coal fly ash by a green approach: influence of synthesis pH. J Hazard Mater. 2006;137(2): 1135-1148.

12. Bhagiyalakshmi M, Yun LJ, Anuradha R, Jang HT. Utilization of rice husk ash as silica source for the synthesis of mesoporous silicas and their application to $\mathrm{CO}_{2}$ adsorption through TREN/TEPA grafting. $J$ Hazard Mater. 2010;175(1-3):928-938.

13. Cho Y, Shi R, Borgens RB, Ivanisevic A. Functionalized mesoporous silica nanoparticle-based drug delivery system to rescue acroleinmediated cell death. Nanomedicine (Lond). 2008;3(4):507-519.

14. Popat A, Hartono SB, Stahr F, Liu J, Qiao SZ, Qing Max Lu G. Mesoporous silica nanoparticles for bioadsorption, enzyme immobilisation, and delivery carriers. Nanoscale. 2011;3(7):2801-2818.

15. Shi J, Votruba AR, Farokhzad OC, Langer R. Nanotechnology in drug delivery and tissue engineering: from discovery to applications. Nano Lett. 2010;10(9):3223-3230.

16. Arruebo M. Drug delivery from structured porous inorganic materials. Wiley Interdiscip Rev Nanomed Nanobiotechnol. 2012;4(1):16-30.

17. Climent E, Bernardos A, Martínez-Máñez R, et al. Controlled delivery systems using antibody-capped mesoporous nanocontainers. J Am Chem Soc. 2009;131(39):14075-14080.

18. Aznar E, Marcos MD, Martínez-Máñez R, et al. pH- and photo-switched release of guest molecules from mesoporous silica supports. J Am Chem Soc. 2009;131(19):6833-6843.

19. Lin LY, Kuo JT, Bai H. Silica materials recovered from photonic industrial waste powder: its extraction, modification, characterization and application. J Hazard Mater. 2011;192(1):255-262.

20. Lin LY, Bai H. Efficient method for recycling silica materials from waste powder of the photonic industry. Environ Sci Technol. 2013;47(9):4636-4643.
21. Al-Attar L, Dyer A, Harjula R. Uptake of radionuclides on microporous and layered ion exchange materials. J Mater Chem. 2003;13:2963-2968.

22. Bore MT, Rathod SB, Ward TL, Datye AK. Hexagonal mesostructure in powders produced by evaporation-induced self-assembly of aerosols from aqueous tetraethoxysilane solutions. Langmuir. 2003;19(2):256-264.

23. Chandrasekar G, You K, Ahn J, Ahn W. Synthesis of hexagonal and cubic mesoporous silica using power plant bottom ash. Microporous Mesoporous Mater. 2008;111(1-3):455-462.

24. Lin YS, Haynes CL. Impacts of mesoporous silica nanoparticle size, pore ordering, and pore integrity on hemolytic activity. J Am Chem Soc. 2010;132(13):4834-4842.

25. He X, Nie H, Wang K, Tan W, Wu X, Zhang P. In vivo study of biodistribution and urinary excretion of surface-modified silica nanoparticles. Anal Chem. 2008;80(24):9597-9603.

26. Napierska D, Thomassen LC, Rabolli V, et al. Size-dependent cytotoxicity of monodisperse silica nanoparticles in human endothelial cells. Small. 2009;5(7):846-853.

27. Koster VS, Kuks PFM, Lange R, Talsma H. Particle size in parenteral fat emulsions, what are the true limitations? Int J Pharm. 1996;134(1-2):235-238.

28. Zhao Y, Sun X, Zhang G, Trewyn BG, Slowing II, Lin VS. Interaction of mesoporous silica nanoparticles with human red blood cell membranes: size and surface effects. ACS Nano. 2011;5(2):1366-1375.

29. Murashov V, Harper M, Demchuk E. Impact of silanol surface density on the toxicity of silica aerosols measured by erythrocyte haemolysis. J Occup Environ Hyg. 2006;3(12):718-723.

30. Lin YS, Haynes CL. Synthesis and characterization of biocompatible and size-tunable multifunctional porous silica nanoparticles. Chem Mater. 2009;21(17):3979-3986.

31. Cunha KS, Reguly ML, Graf U, Rodrigues de Andrade HH. Comparison of camptothecin derivatives presently in clinical trials: genotoxic potency and mitotic recombination. Mutagenesis. 2002;17(2):141-147.

32. Lu J, Liong M, Zink JI, Tamanoi F. Mesoporous silica nanoparticles as a delivery system for hydrophobic anticancer drugs. Small. 2007;3(8):1341-1346.

33. Hon YY, Evans WE. Making TDM work to optimize cancer chemotherapy: a multidisciplinary team approach. Clin Chem. 1998;44(2):388-400.
International Journal of Nanomedicine

\section{Publish your work in this journal}

The International Journal of Nanomedicine is an international, peerreviewed journal focusing on the application of nanotechnology in diagnostics, therapeutics, and drug delivery systems throughout the biomedical field. This journal is indexed on PubMed Central, MedLine, CAS, SciSearch $\AA$, Current Contents ${ }^{\circledR} /$ Clinical Medicine,

\section{Dovepress}

Journal Citation Reports/Science Edition, EMBase, Scopus and the Elsevier Bibliographic databases. The manuscript management system is completely online and includes a very quick and fair peer-review system, which is all easy to use. Visit http://www.dovepress.com/ testimonials.php to read real quotes from published authors. 